\title{
West meets East: dynamic ERCP characterization of pancreaticobiliary maljunction without biliary dilation underlying extensive biliary tract cancer
}
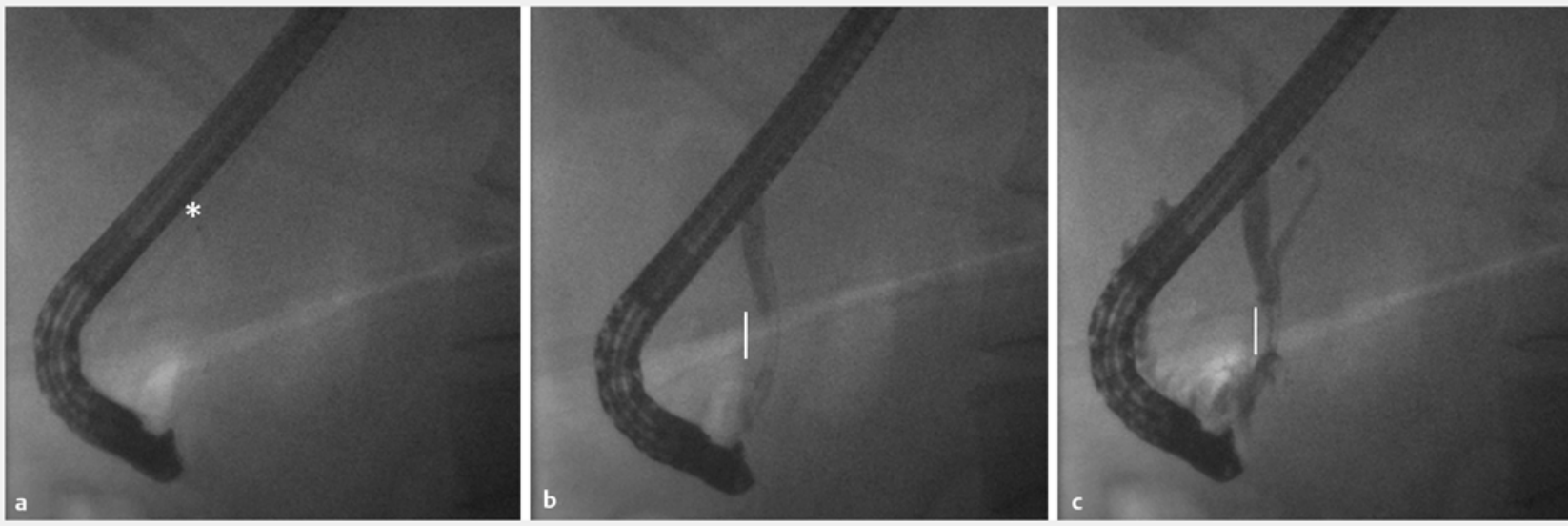

- Fig. 1 Endoscopic retrograde cholangiopancreatography. a The tip of the cannula (asterisk) is visible in the middle portion of the common bile duct (CBD). b The distal CBD during sphincter contraction (bar). $\mathbf{c}$ The pancreatic duct comes to view after increasing injection pressure, confirming a lack of functional pancreaticobiliary duct separation by sphincter activity (bar). Note also lack of proximal CBD/intrahepatic opacification and the ansa pancreatica.

A 62-year-old woman presented with marked cholestasis (bilirubin $9.8 \mathrm{mg} / \mathrm{dL}$ ), and ultrasound suggested intrahepatic biliary dilation down to the hilum and a solid-filled gallbladder. Claustrophobia precluded magnetic resonance imaging, but computed tomography imaging excluded distant metastases. Endoscopic ultrasound suggested an anomalous pancreaticobiliary junction (APBJ) with extramural pancreaticobiliary confluence, a solid gallbladder mass, and an independent, vague $12 \mathrm{~mm}$ hypoechoic hilar lesion, thus suggesting double carcinoma formation in the biliary tract $[1,2]$.

Endoscopic retrograde cholangiopancreatography (ERCP), under antibiotic coverage with oral levofloxacin for 3 days, revealed a long common channel of $12 \mathrm{~mm}$ with associated APBJ. Of note, the pancreaticobiliary ductal junction remained functionally uninterrupted during sphincter contraction, thus favoring true pancreaticobiliary maljunction (PBM) without biliary dilation over high confluence of pancreaticobiliary ducts (HCPBD) (ฉ Fig. 1).

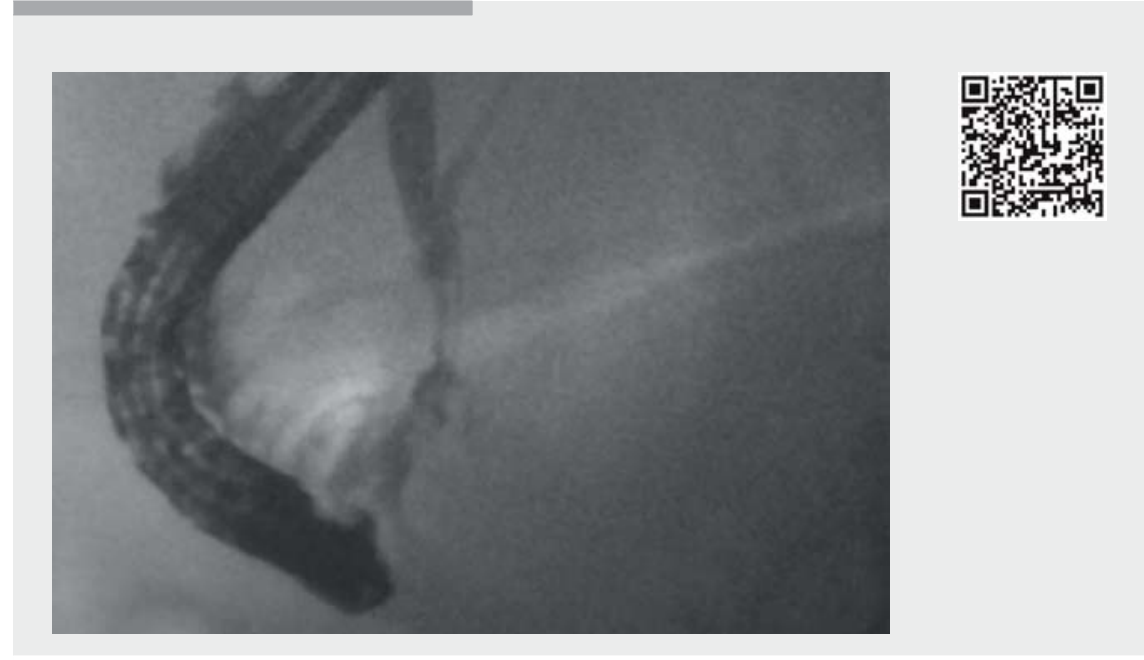

$\checkmark$ Video 1 Video documentation of the endoscopic retrograde cholangiopancreatography procedure, with the tip of the cannula in the middle portion of the common bile duct, providing a dynamic characterization of the anomalous pancreaticobiliary junction. Note that there is constant sphincter contraction throughout the whole sequence, thus confirming lack of functional pancreaticobiliary duct separation. This favored a diagnosis of pancreaticobiliary maljunction without biliary dilation over high confluence of pancreaticobiliary ducts. Please also note the rapidly changing opacification intensity of the pancreatic duct system, dependent on continuous or ceased contrast injection, thereby confirming pancreaticobiliary reflux in accordance with high biliary amylase levels of $8987 \mathrm{U} / \mathrm{L}$. 

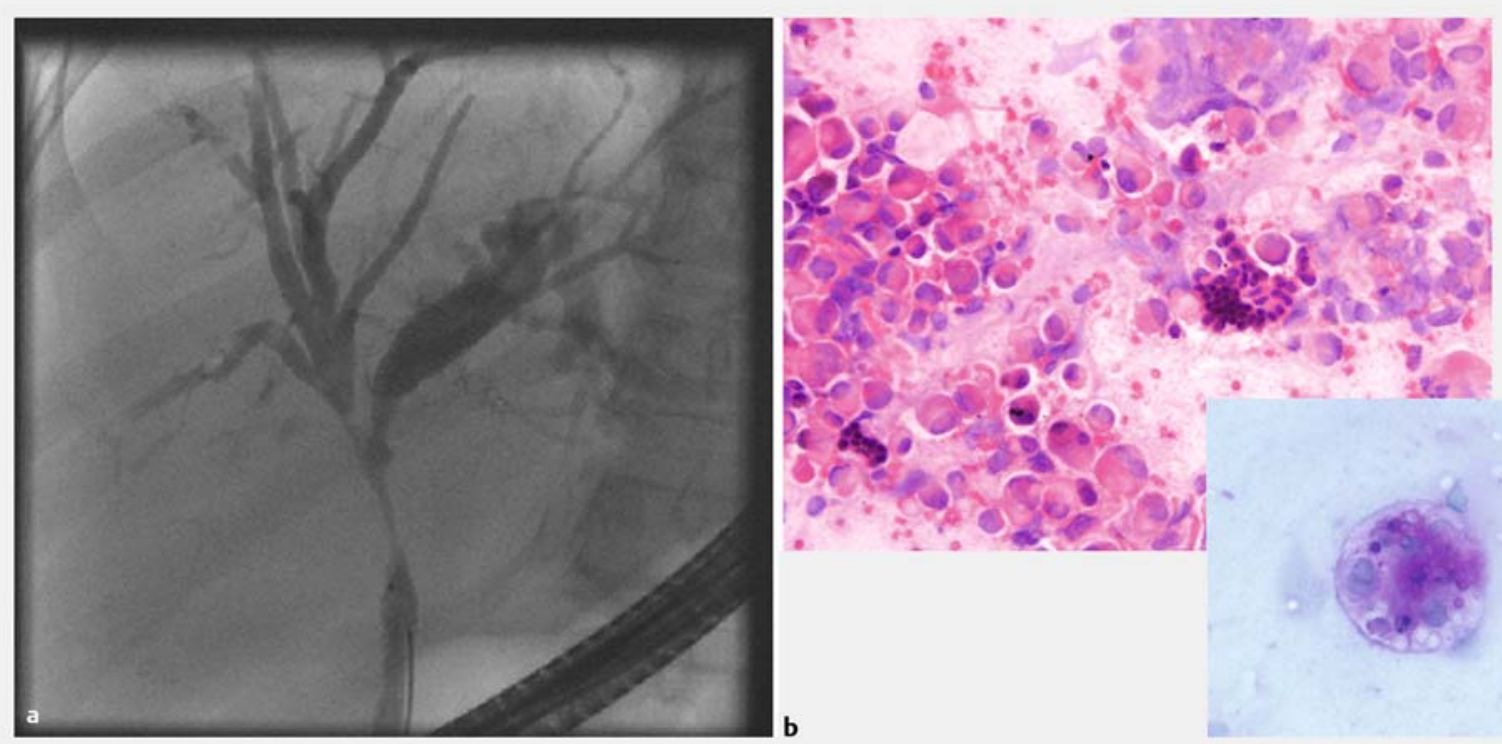

- Fig.2 Malignant hilar stricture complicating pancreaticobiliary maljunction. a Cholangiography indicated an extensive high-grade hilar stricture with interrupted right-left communication consistent with a Bismuth Corlette III lesion. b Aspiration and brush cytology confirmed the presence of adenocarcinoma.

Bile aspirate analysis from the middle portion of the common bile duct indicated high amylase levels of $8987 \mathrm{U} / \mathrm{L}$. - Video 1 shows the in vivo functional characterization of pancreaticobiliary reflux (PBR). Consistent with the pro-carcinogenic effects on the biliary mucosa related to PBR, a high-grade Klatskin lesion was shown on cholangiography, and was confirmed by aspiration and brush cytology (> Fig.2). After bilateral stenting with complete contrast media drainage and slow bilirubin normalization, the patient was referred for hepatobiliary surgery.

APBJ is rare in Western populations and, relative to functional separation capacities of the sphincter apparatus, dichotomizes into PBM (with or without biliary dilation) or HCPBD. In vivo characterization of PBR as backflow of pancreatic juice into the biliary system in PBM had been reported via minor papilla access pancreatography but not by standard, though specifically dedicated, $\operatorname{ERCP}[3,4]$.

Endoscopy_UCTN_Code_CCL_1AZ_2AC

Competing interests

None
The Authors

Vincent Zimmer ${ }^{1,2}$, Christoph Heinrich ${ }^{3}$

1 Department of Medicine, Marienhausklinik St. Josef Kohlhof, Neunkirchen, Germany

2 Department of Medicine II, Saarland University Medical Center, Saarland University, Homburg, Germany

3 Insitute of Pathology Saarbrücken-Rastpfuhl, Saarbrücken, Germany

Corresponding author

\section{Vincent Zimmer, MD}

Department of Medicine, Marienhausklinik St. Josef Kohlhof, Klinikweg 1-5, 66539 Neunkirchen, Germany

Fax: +49-6821-3632624

vincent.zimmer@gmx.de

\section{References}

[1] Kamisawa T, Kuruma S, Chiba K et al. Biliary carcinogenesis in pancreaticobiliary maljunction. J Gastroenterol 2017; 52: 158 163

[2] Suzuki S, Nakamura S, Ochiai H et al. Double cancer of the gallbladder and common bile duct associated with an anomalous pancreaticobiliary ductal junction without a choledochal cyst: report of a case. Surg Today 1999; 29: 651-655
[3] Sugita R. Pancreaticobiliary reflux as a highrisk factor for biliary malignancy: clinical features and diagnostic advancements. World J Hepatol 2015; 7: 1735-1741

[4] Kamisawa T, Ando H, Shimada M et al. Recent advances and problems in the management of pancreaticobiliary maljunction: feedback from the guidelines committee. J Hepatobiliary Pancreat Sci 2014; 21: 87-92

\section{Bibliography}

DOI https://doi.org/10.1055/s-0043-108991

Endoscopy 2017; 49: E175-E176

(c) Georg Thieme Verlag KG

Stuttgart · New York

ISSN 0013-726X

\section{ENDOSCOPY E-VIDEOS}

https://eref.thieme.de/e-videos

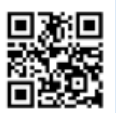

Endoscopy E-Videos is a free access online section, reporting on interesting cases and new techniques in gastroenterological endoscopy. All papers include a high quality video and all contributions are freely accessible online.

This section has its own submission website at

https://mc.manuscriptcentral.com/e-videos 